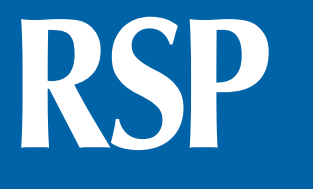

http://www.rsp.fsp.usp.br/

Revista de

Saúde Pública

\title{
Finding Aedes aegypti in a natural breeding site in an urban zone, Sao Paulo, Southeastern Brazil
}

Tamara Nunes Lima-Camara, Paulo Roberto Urbinatti, Francisco Chiaravalloti-Neto

Departamento de Epidemiologia. Faculdade de Saúde Pública. Universidade de São Paulo. São Paulo, SP, Brasil

ABSTRACT

This is the description of how nine Aedes aegypti larvae were found in a natural breeding site in the Pinheiros neighborhood, city of Sao Paulo, SP, Southeastern Brazil. The record was conducted in December 2014, during an entomological surveillance program of dengue virus vectors, with an active search of potential breeding sites, either artificial or natural. Finding Ae. aegypti larvae in a tree hole shows this species' ability to use both artificial and natural environments as breeding sites and habitats, which points towards the importance of maintaining continuous surveillance on this mosquito in all kinds of water-holding containers.

DESCRIPTORS: Aedes, growth \& development. Disease Vectors. Vector Control.

\section{Correspondence:}

Tamara Nunes Lima-Camara

Departamento de

Epidemiologia - FSP-USP

Av. Dr. Arnaldo, 715 Cerqueira César

01246-904 São Paulo, SP, Brasil

E-mail: limacamara@usp.br

Received: 10 mar 2015

Approved: 9 jun 2015

How to cite: Lima-Camara TN,

Urbinatti PR, Chiaravalloti-Neto F.

Finding Aedes aegypti in a natural

breeding site in an urban zone,

Sao Paulo, Southeastern Brazil. Rev

Saude Publica. 2016;50:3.

Copyright: This is an open-access article distributed under the terms of the Creative Commons Attribution License, which permits unrestricted use, distribution, and reproduction in any medium, provided that the original author and source are credited. 


\section{INTRODUCTION}

Aedes (Stegomyia) aegypti (Linnaeus, 1762) is considered a mosquito of great importance to public health care since the early 20th century, when it was found to be a vector of urban yellow fever. Currently, Ae. aegypti is considered the main vector of the four dengue virus serotypes circulating in Brazil (DENV-1, DENV-2 DENV-3, and DENV-4), besides being a competent enough vector to transmit the arboviruses chikungunya and Zika, which have just arrived in the country ${ }^{5}$.

The behavior of this vector is highly endophilic and anthropophilic; it seeks shelter inside houses, where it feeds from human blood. Thus, Ae. aegypti is most frequently found in urban and sub-urban environments, with high concentrations of human beings and houses. Present in all Brazilian states, the females of this species often lay their eggs in rainwater deposits such as artificial containers or objects for domestic use, such as tires, cans, bottles, flower pots, water reservoirs, barrels, vats, abandoned swimming pools and aquariums, among others1. However, albeit rarely, some studies report the finding of Ae. aegypti larvae in bromeliad plants in urban areas ${ }^{2,4}$.

No efficient vaccines are currently available against dengue fever, chikungunya, or Zika. Thus, the only controllable element in the epidemiological chain of these arboviruses is the mosquito, and the main strategy to control that vector mainly includes eliminating its potential breeding sites ${ }^{3}$.

This study aimed to report the finding of Ae. aegypti larvae in a natural breeding site in an urban area of the city of Sao Paulo, during entomological surveillance procedures.

\section{METHODS}

An active search for Ae. aegypti immatures was conducted in both artificial and natural breeding sites on December 3, 2014, in an urban area located in the Pinheiros neighborhood, city of Sao Paulo, SP, Southeastern Brazil, which is a very busy area.

Plastic ladles with maximum capacity of $80 \mathrm{ml}$ were used to collect the immatures. The material collected with the ladles was transferred to plastic containers labeled according to the types of breeding sites, and then sent to an entomology laboratory. The collected larvae were identified under a stereo microscope, according to the dichotomous key proposed by Consoli and Lourenço de Oliveira ${ }^{1}$ (1994).

\section{RESULTS}

Nine larvae in the L4 stage were collected in a hole of a tree that belonged to the Moraceae family and to the Ficus genus (Figure, A and B). All nine larvae were identified as Ae. aegypti and kept in a laboratory until they fully matured, when their species was confirmed.

\section{DISCUSSION}

In Brazil, field studies with Ae. aegypti show that this mosquito is more frequently captured inside houses, and female mosquitoes are found to be engorged with human blood. That reinforces the endophilic and anthropophilic behaviors of that species ${ }^{1}$. Besides that, finding Ae. aegypti in immature stages is more frequent in artificial breeding sites in urban and sub-urban areas, although larvae of this species have already been found in natural breeding sites, such as bromeliad plants ${ }^{2,4}$.

This study reports the finding of nine Ae. aegypti larvae in a tree hole near some houses, during a search for potential breeding sites of this vector in the area. Finding L4 stage Ae. aegypti 

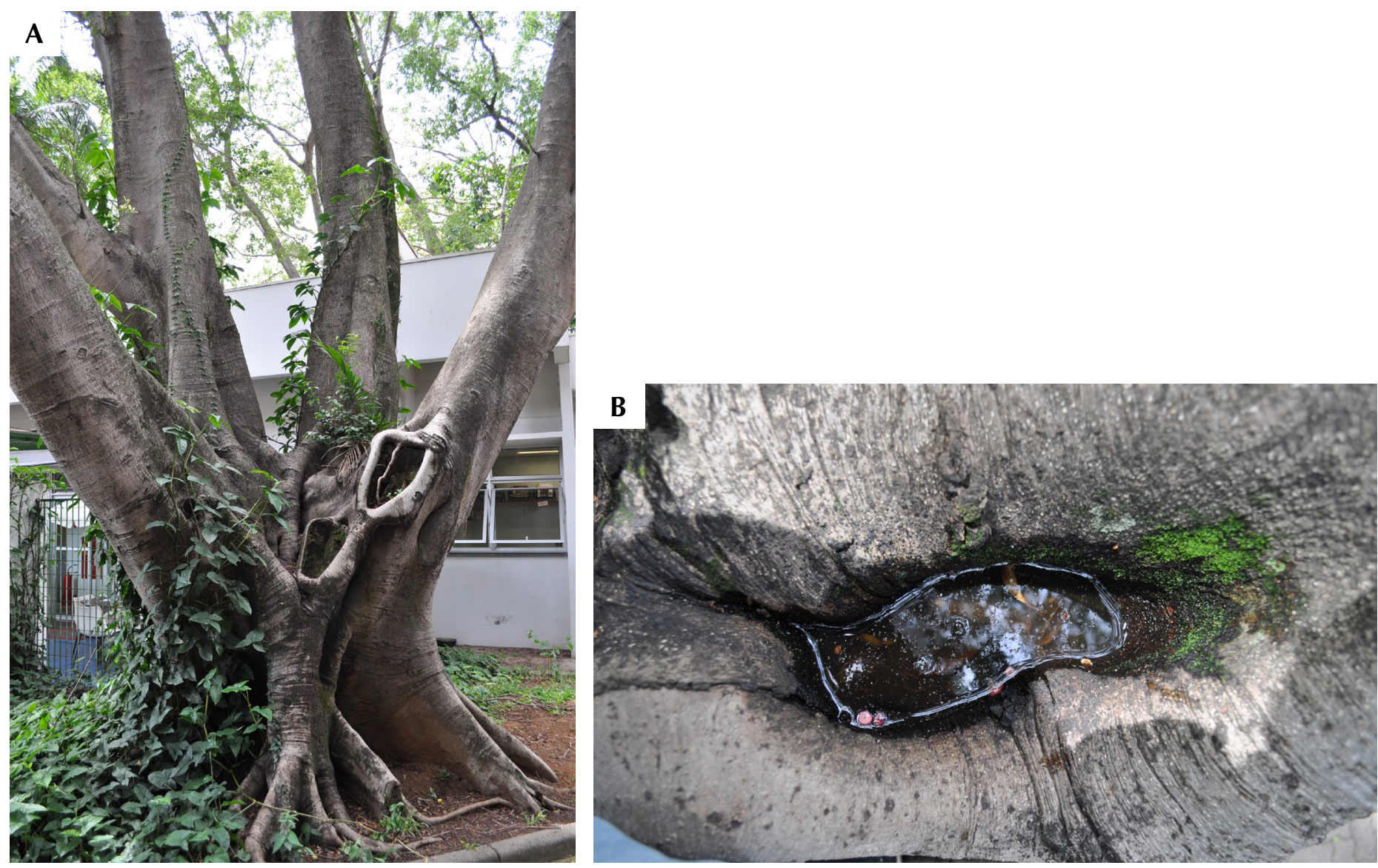

Figure. Natural breeding site with Ae. aegypti larvae. (A) Partial view of the tree located in a garden in the Pinheiros neighborhood, where the nine Ae. aegypti larvae were found. (B) Detail of the tree hole from where the larvae were collected.

larvae in a natural breeding site points towards two important aspects. The first is that entomological surveillance on this species in artificial containers may have been efficient, as the reduced availability of that type of breeding site causes Ae. aegypti to seek other places to lay its eggs. The second aspect is the confirmed plasticity of this vector, which, in the absence of artificial breeding sites, lays its eggs in natural breeding sites, a behavior that is not very usual for this species.

In conclusion, it is necessary to maintain entomological surveillance on Ae. aegypti not only in artificial containers but also in natural water-holding surfaces, even in urban areas, to keep outbreaks of arboviruses such as dengue, chikungunya, and Zika controlled.

\section{REFERENCES}

1. Consoli RAGB, Lourenço-de-Oliveira R. Principais mosquitos de importância sanitária no Brasil. Rio de Janeiro (RJ): Editora Fiocruz; 1994.

2. Forattini OP, Marques GRAM. Nota sobre o encontro de Aedes aegypti em bromélias. Rev Saude Publica. 2000;34(5):543-4. DOI:10.1590/S0034-89102000000500016

3. Tauil PL. Urbanização e ecologia do dengue. Cad Saude Publica. 2001;17(suppl):S99-S102. DOI:10.1590/S0102-311X2001000700018

4. Varejão JB, Santos CB, Rezende HR, Bevilacqua LC, Falqueto A. Aedes (Stegomyia) aegypti (Linnaeus, 1762) breeding sites in native bromeliads in Vitória City, ES. Rev Soc Bras Med Trop. 2005;38(3):238-40. DOI:10.1590/S0037-86822005000300006

5. Vega-Rúa A, Zouache K, Girod R, Failloux AB, Lourenço-de-Oliveira R. High vector competence of Aedes aegypti and Aedes albopictus from ten American countries as a crucial factor of the spread of Chikungunya. J Virol. 2014;89(14):6294-306. DOI:10.1128/JVI.00370-14 
Funding: Fundação de Amparo à Pesquisa do Estado de São Paulo (FAPESP - Process 2014/05016-5).

Acknowledgments: To Sabrina Ribeiro Santana, Amanda Aparecida de Jesus Freitas, Patricia Marques Moralejo Bermudi, Rodrigo Meirelles, and Thiago Henrique da Silva for their entomological surveillance work and for finding the larvae.

Author's Contributions: Collection and identification of the larvae: PRU. Drafting of the manuscript: TNL-C. Critical and intellectual review of the manuscript: TNL-C, FC-Neto, and PRU. Approval of the final draft of the manuscript to be published: TNL-C, FC-Neto, and PRU.

Conflict of Interest: The authors declare no conflict of interest. 